\title{
Distribution and Biodiversity of Australian Tropical Marine Bioinvasions $^{1}$
}

\author{
Chad L. Hewitt ${ }^{2}$
}

\begin{abstract}
Marine invasions have been identified in virtually all regions of the world, yet relatively few introductions have been detected in the Tropics. This has been attributed at least in part to an increase in intrinsic native community resistance at lower latitudes resulting from strongly interacting food webs in high(er) diversity systems. However, recent evidence from surveys in Australia and elsewhere indicate that tropical systems are also susceptible to invasions, though detection ability may be constrained by taxonomic limitations. Preliminary analyses of data from surveys designed to detect introduced species do not support a pattern of decreased invasion success in higher diversity systems but do indicate a strong latitudinal gradient at the mesoscale of Australia. This cannot be attributed to disparities in search effort (controlled for by consistency in survey effort) or taxonomic knowledge. The original hypothesis of a decreased relative susceptibility of tropical versus temperate biota to invasions may remain viable, but be scale dependent. Additional confounding factors may include differing vector strengths and availability of source bioregions.
\end{abstract}

The INTENTIONAL AND accidental transport and introduction of marine species to new regions is currently perceived to be one of the primary threats to biological diversity (Hatcher et al. 1989, Lubchenco et al. 1991, Norse 1993, Suchanek 1994). Yet we currently do not have the necessary data to determine if the observed patterns of these introductions are a result of real differences between systems or merely reflect artifacts of sampling effort or identification ability. Marine (and estuarine) biological introductions have been detected in all oceans of the world (Pollard and Hutchings 1990a,b, Carlton 1996b, Ruiz et al. 1997, 2000, Hewitt et al. 1999), yet relatively few marine introductions

${ }^{1}$ Paper presented at the Ninth International Coral Reef Symposium, Bali, Indonesia, 27 October 2000. Manuscript accepted 5 September 2001.

${ }^{2}$ CSIRO Marine Research, Centre for Research on Introduced Marine Pests, GPO Box 1538, Hobart, Tasmania 7001, Australia (telephone: (+61 3) 6232 5102; fax: (+61 3) 6232 5485; E-mail: chad.hewitt@marine. csiro.au).

Pacific Science (2002), vol. 56, no. 2:213-222 (C) 2002 by University of Hawai'i Press. All rights reserved have been detected in the Tropics (but see Coles et al. 1999a,b and Paulay et al. in press). This has been attributed, in large part, to the higher diversity of native tropical communities conferring an increased resistance to invasions through an increase in biotic interactions (sensu Elton 1958). Other hypotheses exist that might also explain the observed patterns: tropical systems have been less well surveyed, resulting in fewer detected invasions. Alternatively, the existing taxonomic knowledge in the Tropics is insufficiently advanced to aid in the recognition of invading species in most groups.

Recent evidence indicates that tropical systems are susceptible to introductions that can be as spectacular as well-known examples from higher latitudes such as the North American ctenophore Mnemiopsis leidyi into the Black Sea (Vinogradov et al. 1989); the Asian clam Potamocorbula amurensis into San Francisco Bay, California (Carlton et al. 1990); and the northern Pacific seastar Asterias amurensis invasion in southeastern Australia (Buttermore et al. 1994, Talman et al. 1999). The Caribbean barnacle Cbthamalus proteus has successfully invaded the Hawaiian Islands and spread to intertidal habitats but does not appear to have caused substantial alterations to the 
community (Southward et al. 1998). Similarly, the black-striped "mussel" Mytilopsis sallei has invaded port communities throughout the Indo-Pacific and has most recently been introduced into (and subsequently eradicated from) the Port of Darwin, Australia (Bax 1999, Willan et al. 2000).

Two primary methods exist to identify patterns of invasions: literature and/or specimen collection evaluations; and field surveys, targeting those habitats and areas most linked with overseas vectors of transport. Literature and museum collection evaluations provide the broadest coverage for a region, but these are typically inconsistent in both coverage and effort. Patterns derived from these sources alone can result in misleading indications of invasion strength and rate (Coles et al. 1999a). In 1995 the CSIRO Centre for Research on Introduced Marine Pests (CRIMP) began a series of baseline introduced species surveys of commercial, internationally trading ports. The primary aims of this project have been to assess the degree to which Australian coastal waters have become invaded and to determine the extent to which these introduced species still pose a threat of further spread in Australia. More than 25 surveys have been conducted by a variety of organizations in all primary biogeographic provinces of Australia using a consistent survey design and methodology (Hewitt and Martin 1996, 2001).

In this paper, tropical and temperate invasions of Australian coastal waters are compared based on eight CRIMP-conducted introduced species surveys. In doing so, the second hypothesis presented earlier (survey intensity) is controlled for through consistency in sampling design and effort. The apparent patterns are discussed relative to the remaining two hypotheses.

\section{MATERIALS AND METHODS}

\section{Survey Design and Sampling Methodologies}

The protocols and considerations for designing and implementing introduced species surveys of commercial ports of first call (international trading ports) have been developed in detail elsewhere (Hewitt and Martin
1996, 2001). A summary of the survey design considerations and protocols for methodologies is presented here. Survey design critically relies upon an explicit development of the questions being asked and the objectives of the survey. Although a systematic survey of all habitats in port environments is the only approach likely to detect all introduced species, the resources required to undertake such a survey are generally unavailable. Surveys must therefore balance detection probability with resource expenditure. Recognition of these constraints has led to the adoption of a strategy that concentrates on high-probability inoculation sites (see Hewitt and Martin 1996, 2001).

Several sampling methods are used to evaluate the presence of introduced species in a variety of habitats (Table 1). Hard substrates in commercially active port areas are typically represented by anthropogenic structures such as piles, breakwalls and facings, and occasionally natural reefs. Species in these habitats include sessile and mobile epibenthic fauna and flora. Soft substrates range from soft silty clay, mud, sand to gravel and cobble. These habitats are frequently disturbed in many port environments due to dredging activities and propeller wash from tugs and commercial vessels. Species include sessile and mobile epibenthos, infauna, and dinoflagellate cysts.

\section{Analyses of Survey Outcomes}

The port surveys reported on here were conducted by CRIMP in conjunction with other organizations (Darwin, Northern Territory [NT]: Museum and Art Gallery of the Northern Territory; Eden and Newcastle, New South Wales [NSW]: New South Wales Fisheries Research Institute; Fremantle, Western Australia [WA]: Murdoch University) or alone (Bunbury and Port Hedland, WA; Hay Point and Mackay, Queensland [QLD]) (Figure 1). Taxa were sorted and identified to least taxonomic unit (species where possible) and introductions identified following the criteria of Chapman and Carlton $(1991,1994)$. Those species whose native or introduced status remains unclear were deemed cryptogenic (sensu Carlton 1996a). 
TABLE 1

Appropriate Sampling Techniques for the Detection of Introduced Species in Different Port Habitats

\begin{tabular}{|c|c|c|c|c|c|}
\hline \multirow[b]{2}{*}{ Sampling Technique } & \multicolumn{5}{|c|}{ Habitat } \\
\hline & $\begin{array}{c}\text { Soft } \\
\text { Substrate }\end{array}$ & $\begin{array}{c}\text { Hard } \\
\text { Substrate }\end{array}$ & $\begin{array}{c}\text { Seagrass/ } \\
\text { Macroalgal } \\
\text { Bed }\end{array}$ & $\begin{array}{l}\text { Plankton/ } \\
\text { Nekton }\end{array}$ & $\begin{array}{l}\text { Beach } \\
\text { Wrack }\end{array}$ \\
\hline Small cores & $\mathrm{X}$ & & & & \\
\hline Large cores & $\mathrm{X}$ & & $\mathrm{X}$ & & \\
\hline $20-\mu \mathrm{m}$ plankton net & & & & $\mathrm{x}$ & \\
\hline $100-\mu \mathrm{m}$ drop net & & & & $\mathrm{x}$ & \\
\hline Traps: crab/shrimp & $\mathrm{X}$ & $\mathrm{X}$ & $\mathrm{X}$ & $\mathrm{X}$ & \\
\hline Qualitative visual surveys & $X$ & $\mathrm{X}$ & $\mathrm{x}$ & & $x$ \\
\hline Quadrat scraping & & $\mathrm{X}$ & & & \\
\hline Video and photo transects & $\mathrm{X}$ & $\mathrm{X}$ & $\mathrm{x}$ & & \\
\hline Beam trawl/Benthic sled & $\mathrm{X}$ & & $\mathrm{x}$ & & \\
\hline Poison stations & $\mathrm{X}$ & $\mathrm{X}$ & $\mathrm{X}$ & $\mathrm{x}$ & \\
\hline Beach seines & $X$ & & $\mathrm{X}$ & $\mathrm{X}$ & \\
\hline
\end{tabular}

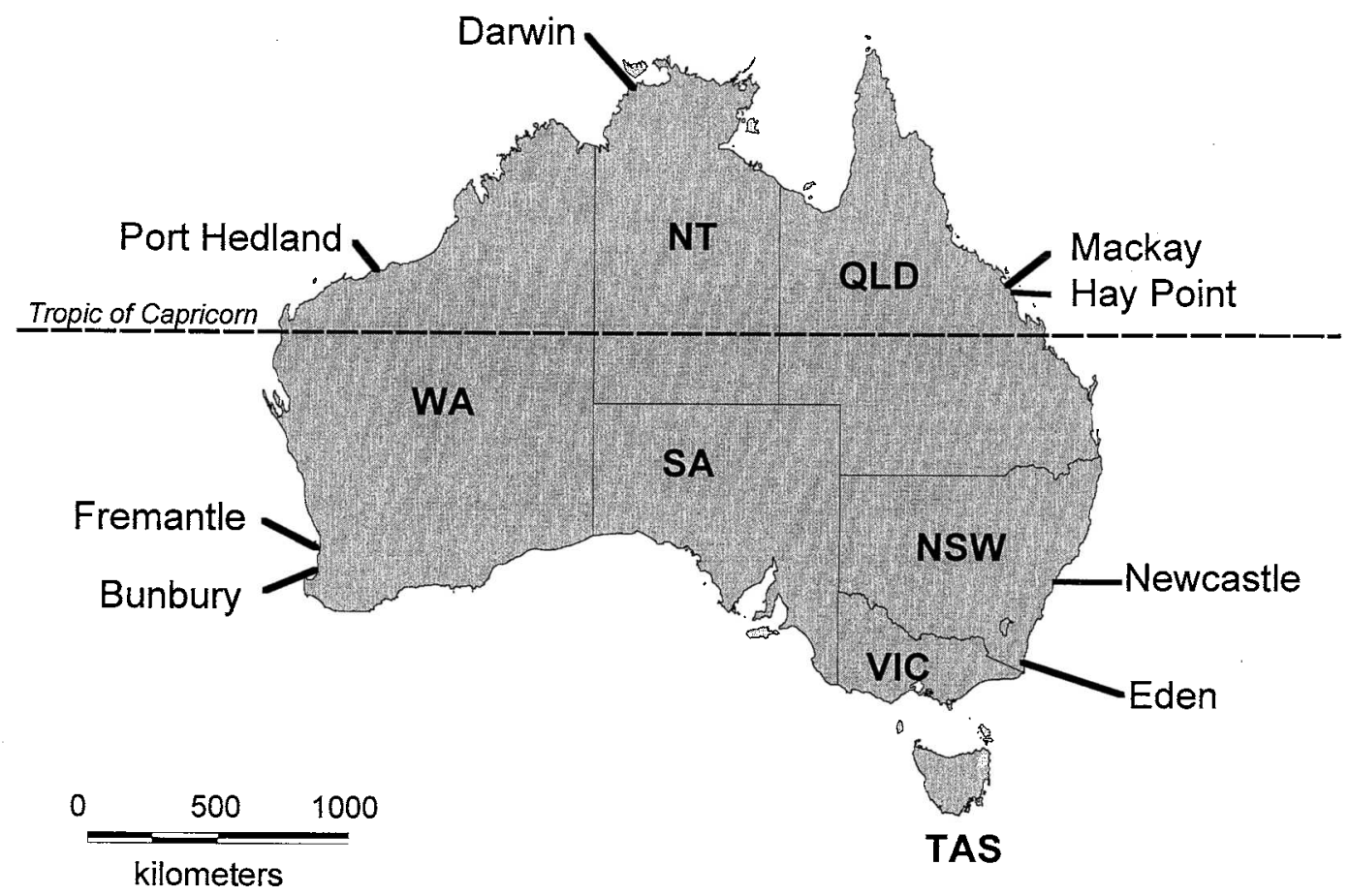

FIGURE 1. Locations of introduced species port surveys in Australia reported here. Note the Tropic of Capricorn at $23^{\circ} \mathrm{S}$. 
TABLE 2

Introduced and Cryptogenic Species Collected in the Eight Port Surveys

\begin{tabular}{|c|c|c|c|c|}
\hline Taxa & Origin/Range & HF & Tropical & Temperate \\
\hline \multicolumn{5}{|l|}{ Annelida } \\
\hline \multicolumn{5}{|l|}{ Polychaeta } \\
\hline Ficopomatus enigmaticus & Cosmopolitan; NE Atlantic & + & - & + \\
\hline Hydroides elegans & Cosmopolitan; NE Atlantic & + & + & + \\
\hline Hydroides ezoensis & Cosmopolitan; NE Atlantic & + & - & + \\
\hline Proscoloplos sp. & - & & - & + \\
\hline Sabella spallanzanii & Mediterranean & + & - & + \\
\hline \multicolumn{5}{|l|}{ Arthropoda } \\
\hline \multicolumn{5}{|l|}{ Amphipoda } \\
\hline Caprella equilibra & NE Atlantic & + & - & + \\
\hline Coropbium sextonae & New Zealand? & & - & + \\
\hline \multicolumn{5}{|l|}{ Cirripedia } \\
\hline Balanus ampbitrite & Cosmopolitan; Red Sea & + & + & - \\
\hline Megabalanus rosa & NW Pacific & + & - & + \\
\hline Megabalants tintinnabulum & Cosmopolitan & + & + & - \\
\hline Notomegabalanus algicola & South Africa & + & - & + \\
\hline \multicolumn{5}{|l|}{ Decapoda } \\
\hline Cancer novaezelandiae & New Zealand & & - & + \\
\hline Carcinus maenas & NE Atlantic & & - & + \\
\hline Elemana gordonae & E Indian Ocean & & + & - \\
\hline Halicarcinus bondai & NW Pacific & & + & - \\
\hline \multicolumn{5}{|l|}{ Isopoda } \\
\hline Paracerceis sculpta & E Pacific & + & + & + \\
\hline Paradella dianae & NE Pacific & + & + & - \\
\hline \multicolumn{5}{|l|}{ Chordata } \\
\hline \multicolumn{5}{|l|}{ Ascidiacea } \\
\hline Botrylloides leachi & NE Atlantic & + & + & + \\
\hline Styela plicata & W Pacific & + & - & + \\
\hline \multicolumn{5}{|l|}{ Cnidaria } \\
\hline Antenella secundaria & Cosmopolitan & + & + & - \\
\hline Bougainvillia muscus (= ramosa) & NE Atlantic & + & - & + \\
\hline Clytia bemispbaerica & Cosmopolitan & + & - & + \\
\hline Clytia paulensis & N Atlantic; South Africa & + & - & + \\
\hline Ectopleura crocea & NW Atlantic & + & - & + \\
\hline Halecium delicatulum & Cosmopolitan & + & - & + \\
\hline Obelia dicbotoma (= australis) & Cosmopolitan; NE Atlantic & + & + & + \\
\hline Obelia longissima & Cosmopolitan; NE Atlantic & + & + & - \\
\hline Pbialella quadrata & Cosmopolitan & + & - & + \\
\hline Plumularia setecea & Cosmopolitan & + & - & + \\
\hline Sarsia radiata & Cosmopolitan; NE Atlantic & + & - & + \\
\hline Sertularia malayensis & — & + & + & - \\
\hline Sertularia ortbogonalis & - & + & + & - \\
\hline \multicolumn{5}{|l|}{ Dinophyta } \\
\hline Alexandrium catenella & Cosmopolitan & & + & + \\
\hline Alexandrium minutum & Mediterranean; NE Atlantic & & - & + \\
\hline \multicolumn{5}{|l|}{ Ectoprocta } \\
\hline Amatbia distans & Cosmopolitan; NE Atlantic & + & + & - \\
\hline Bowerbankia cf. gracilis & Cosmopolitan; NE Atlantic & + & + & + \\
\hline Bugula flabellata & NE Atlantic & + & + & + \\
\hline Bugula neritina & Cosmopolitan; NE Atlantic & + & + & + \\
\hline Bugula stolonifera & Cosmopolitan & + & + & + \\
\hline Celleporaria bastigera & - & + & - & + \\
\hline Celleporella byalina & NW Pacific & + & - & + \\
\hline Conopeum seurati & N Atlantic & + & - & + \\
\hline Cryptosula pallasiana & Cosmopolitan; N Atlantic & + & + & \\
\hline Onconsoecia sp. & NE Pacific & + & - & + \\
\hline
\end{tabular}


TABLE 2 (continued)

\begin{tabular}{|c|c|c|c|c|}
\hline Taxa & Origin/Range & $\mathrm{HF}$ & Tropical & Temperate \\
\hline Onconsoecia sp. & NE Pacific & + & - & + \\
\hline Membranipora membranacea & Cosmopolitan; NE Pacific & + & - & + \\
\hline Schizoporella errata & Cosmopolitan; NW Atlantic & + & + & + \\
\hline Scbizoporella sp. A & - & + & - & + \\
\hline Scbizoporella unicornis & Cosmopolitan; NW Pacific & + & + & + \\
\hline Tricellaria occidentalis (= porteri) & N Pacific & + & + & + \\
\hline Watersipora arcuata & E Pacific & + & + & + \\
\hline Watersipora subtorquata & W Pacific & + & + & + \\
\hline Zoobotryon verticellatumn & Cosmopolitan & + & + & + \\
\hline \multicolumn{5}{|l|}{ Mollusca } \\
\hline \multicolumn{5}{|l|}{ Bivalvia } \\
\hline Crassostrea gigas & NW Pacific & + & - & + \\
\hline Musculista senbousia & NW Pacific & + & + & + \\
\hline Mytilopsis sallei & Caribbean & + & + & - \\
\hline Mytilus galloprovincialis & NE Atlantic; Mediterranean & + & - & + \\
\hline \multicolumn{5}{|l|}{ Gastropoda } \\
\hline Maoricolpus roseus & New Zealand & & - & + \\
\hline Polycera capensis & South Africa & + & - & + \\
\hline
\end{tabular}

Note: +, Presence; -, absence in fouling communities. HF $=$ hull-fouling species.

Voucher specimens of all materials are maintained in the CRIMP port survey collection at the CSIRO Marine Laboratories. The numbers of native and introduced species (species richness) were tallied for each individual port and world distributions were determined from the literature.

\section{RESULTS}

A total of 58 introduced species was detected in the eight port surveys reported here; 28 (49.2\% of all detected introduced species) were detected in the four tropical ports, and $48(81.4 \%$ of all detected introduced species) were found in the temperate ports (Table 2). Only 11 introduced taxa were restricted to the tropical ports. Tropical invaders included representatives from seven phyla, the most prevalent of which were ectoprocts (12), arthropods (6), and hydroids (5). Twenty-eight of the tropical species had been reported previously for Australian waters, the sole exception being the dreissenid bivalve Mytilopsis sallei. Most of the tropical introduced species (49 species or $84.7 \%$ ) are fouling or encrusting species that are capable of being transported on the hulls of vessels. Sixteen new records for Australia were identified in the tropical surveys (Table 3).

Taxonomic experts could not identify (Table 3) a substantial component of material collected during the surveys to species (34 to $75 \%$ ). Although many of these taxa are likely to be native to Australia, they have not been rigorously evaluated to determine their native or introduced status and therefore must be considered to be cryptogenic (native origin unknown, sensu Carlton 1996a). The percentage of unresolved taxa does not significantly increase at lower latitudes $\left(r^{2}=0.151\right.$; $F=1.14 ; \mathrm{df}=1,6 ; P=0.32$ ), and there are no differences between tropical and temperate ports (arcsine square-root transformed percentage data: $t=1.36, \mathrm{df}=6, P>0.05$ ).

Species richness in each port was regressed against latitude on the east and west coasts of Australia. No differences were detected between east and west coast sites for either native $(t=1.64, \mathrm{df}=6, P>0.05)$ or introduced $(t=0.17, \mathrm{df}=6, P>0.05)$ species richness. Total species richness increases toward the Tropics (Figure 2a: $r^{2}=0.376$ ), but the regression is not significant $(F=3.61$; $\mathrm{df}=1,6 ; P=0.106)$. In contrast, a significant $(F=7.26 ; \mathrm{df}=1,6 ; P=0.036)$ increase in 
TABLE 3

Port Survey Results: Numbers of Native and Introduced Species, Unidentified Species, and New Records

\begin{tabular}{lcccc}
\hline \hline Location & Native Spp. & Introduced Spp. & $\begin{array}{c}\text { Estimated } \\
\text { Unidentified Spp. }\end{array}$ & $\begin{array}{c}\text { New Records and } \\
\text { New Species }\end{array}$ \\
\hline Darwin, NT & 879 & 5 & $\sim 300$ & 8 \\
Port Hedland, WA & 548 & 16 & $\sim 310$ & 0 \\
Fremantle, WA & 783 & 33 & $\sim 590$ & 5 \\
Bunbury, WA & 250 & 12 & $\sim 120$ & 0 \\
Mackay, QLD & 380 & 12 & $\sim 145$ & 5 \\
Hay Point, QLD & 496 & 10 & $\sim 190$ & 3 \\
Newcastle, NSW & 366 & 25 & $\sim 185$ & 0 \\
Eden, NSW & 237 & 24 & $\sim 100$ & 1 \\
\hline
\end{tabular}

invasion strength is apparent with increasing latitude (Figure $2 b: r^{2}=0.547$ ). Introduced species richness appears to be inversely correlated with native species richness, but the relationship is not significant (Figure $3: r^{2}=$ $0.005 ; F=0.03$; df $=1,6 ; P=0.867)$.

The origins of introduced species are difficult to discern, but presumed native regions have been recorded in Table 2 . Both tropical and temperate invasions comprise a large number of species with cosmopolitan distributions ( 51.7 and $39.6 \%$, respectively). Many of these cosmopolitan species can also be attributed to specific regions of origin (Table 2 ). When combined with species of more limited worldwide distribution, no apparent differences between origins of tropical and temperate invasions can be discerned except for those regions that contributed species to only tropical (West Indian Ocean and Red Sea and the Caribbean) or only temperate ports (the Mediterranean, South Africa, and New Zealand) (Figure 4).

\section{DISCUSSION}

Australia has received introductions from a variety of source regions (Hewitt et al. 1999) and transport vectors during the $400 \mathrm{yr}$ since initial European contact (Crosby 1986, Campbell and Hewitt 1999). This is evident in the variety of origins represented for known introductions in Australian coastal waters (Hewitt et al. 1999; Table 2). Reviews of literature, museum collections, and surveys for introduced species have detected at least one introduced species in all coastal Australian marine bioregions (Hewitt et al. 1999). These introductions appear to be highest in temperate regions and decrease toward the Tropics.

Three hypotheses were identified as alternate explanations for this pattern of decreased marine invasions in tropical waters. The hypothesis that tropical systems have been less well surveyed, resulting in fewer detected invasions was controlled for in this study through the use of data collected in a consistent sampling effort across all eight ports.

The question of a disparity in taxonomic knowledge between tropical and temperate systems is not supported by these survey results. Large numbers of taxa collected in both temperate and tropical ports could not be resolved to species and no significant differences were detected. The preliminary tally of new records for Australia (16 in the Tropics and 6 in temperate sites) demonstrates a high level of taxonomic expertise in a diverse array of groups. Nonetheless, taxonomic expertise is limited in Australia, and little funding is available for training.

The current paradigm revolves around the first hypothesis: that higher diversity (native) systems have an increased biotic resistance to invasions. The concept of biotic resistance is primarily supported by mathematical models (Drake 1990, Case 1991) and has received only moderate support from field studies (Robinson et al. 1995; but see Stachowicz et al. 1999), and a general consensus has yet to be reached (Williamson 1996). This hypothesis is not unequivocally supported by 
a

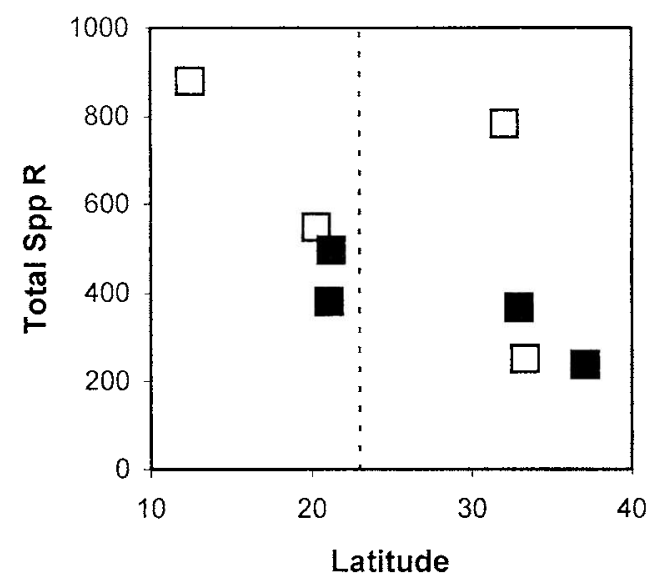

b

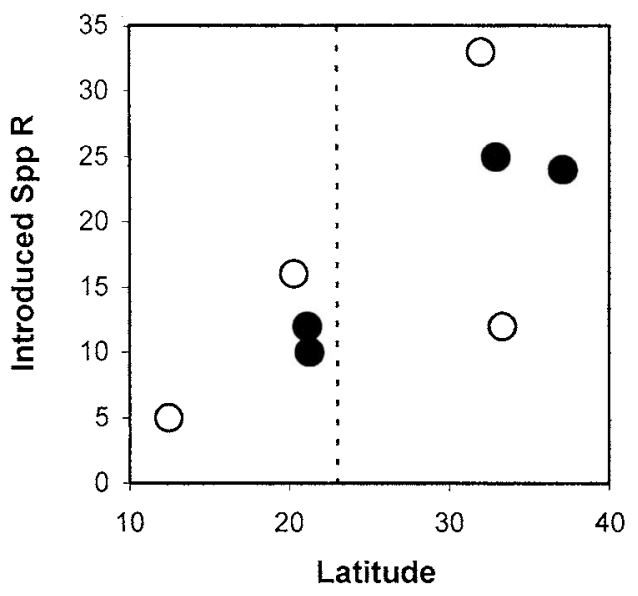

FIGURE 2. Relationship between species richness and latitude for (a) native species richness ( $\square$ ) and $(b)$ introduced species richness $(O)$ in east $(\boldsymbol{\square}, \bullet)$ and west $(\square, O)$ coast ports.

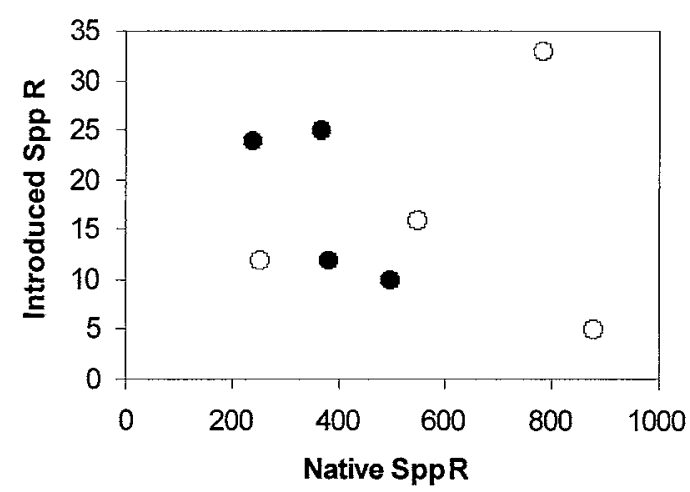

FIGURE 3. Relationship between native and introduced species richness in port surveys of east $(\mathbf{0})$ and west $(O)$ coast ports.

the data presented here. Although a negative relationship between introduced and native species richness is apparent in Figure 3, the slope of the regression line is not significantly different from zero. This may be due, in part, to the scale at which comparisons are being made. Unlike Stachowicz et al. (1999), who evaluated resistance at the scale of $100 \mathrm{~cm}^{2}$, this study provides summary data at the level of the individual ports. It is likely that biotic

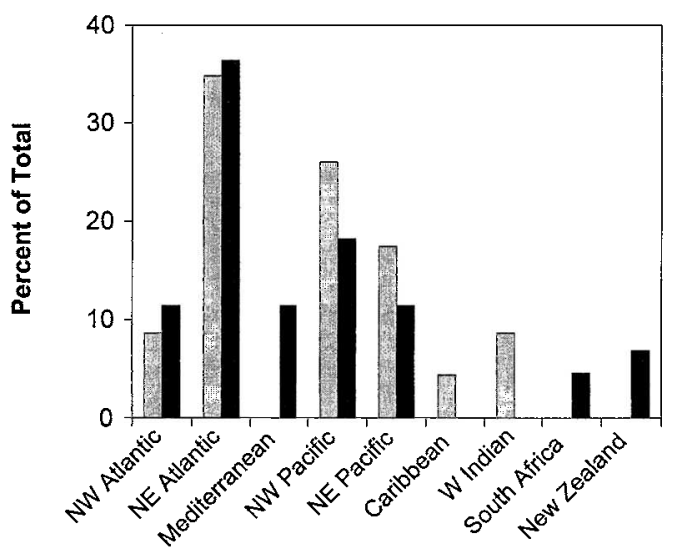

Figure 4. Origins of introduced species detected in tropical (light shaded bars) and temperate (dark shaded bars) port surveys.

resistance operates at the level of the community and comparisons should be conducted between individual berths or even between $0.10-\mathrm{m}^{2}$ quadrats. The original hypothesis of a decreased relative susceptibility of tropical versus temperate biota to invasions may remain viable, but may be scale dependent, as indicated by Drake (1990).

Several confounding factors may act to create differences between tropical and tem- 
perate waters. The strength of individual introduction vectors appears to vary between the two regions. Hewitt et al. (1999) reported that approximately $60 \%$ of the invasions into Port Phillip Bay were associated with hull fouling. In the tropical invasions reported here, $84.7 \%$ are associated with hull fouling. In addition, trading activities in the two regions have acted to create historic differences in the availability of source bioregions for introductions; the majority of trade to Australia has been from Northern Hemisphere, temperate bioregions, favoring temperate introductions rather than tropical ones.

A gross level evaluation of introduced species richness regressed against latitude suggests that eight new introductions are accumulated with every 10 degrees of increased latitude (Figure 2b). This evaluation, however, ignores the substantial change in species composition of introduced species between sites. Until additional, rigorous surveys are conducted in other tropical regions it will be impossible to determine if the pattern observed here is a result of ecological resistance or differential inoculation pressure.

\section{CONCLUSIONS}

1. Based on surveys that account for differential search effort, no significant difference between the number of identified invasions of tropical and temperate regions can be detected.

2. The recognition of biological invasions relies on a critical linkage between ecology and taxonomy. Without additional resources for taxonomic activity and training, the science of invasion biology will be limited in its ability to detect pattern and develop predictive models.

3. The current invasion biology paradigm, that increased native species diversity results in an increased biotic resistance to invasions, is not supported by this study. The scale of the evaluation may, however, influence this result.

4. A strong latitudinal gradient in marine invasions exists that may be related to a combination of native species diversity, differen- tial strength of transport vectors, and access to source bioregions.

5. Hull fouling continues to play an important role in new invasions and may be responsible for more new invasions in tropical Australia than other vectors (e.g., ballast water-mediated inoculations).

6. The evaluation of marine bioinvasions requires the development of a rigorous suite of survey standards and sampling methodologies that eliminates sampling artifacts and facilitates the comparison of regional patterns of invasion susceptibility.

\section{ACKNOWLEDGMENTS}

I acknowledge the many people who aided in collection of these data: the CRIMP Port Survey Team consisting of M. L. Campbell, F. McEnnulty, K. Moore, N. Murfet, B. Robertson, and others who participated in the various surveys. The surveys were funded in part by the various Port Authorities (Ports Corporation Queensland [Hay Point], Mackay Port Authority, Port Hedland Authority, Fremantle Port Authority, Bunbury Port Authority, Newcastle Port Corporation), State/'Territory Departments (Northern Territory Department of Transport and Works [Darwin] and NSW Department of Transport [Eden]), and the Australian Quarantine and Inspection Service (AQIS) Ballast Water Group. My thanks also to Richard Martin and Marnie Campbell for providing comments on the manuscript.

\section{Literature Cited}

Bax, N. 1999. Eradicating a dreissenid from Australia. Dreissena! 10:1-5.

Buttermore, R. E., E. Turner, and M. G. Morrice. 1994. The introduced northern Pacific seastar Asterias amurensis in Tasmania. Mem. Queensl. Mus. 36:21-25.

Campbell, M. L., and C. L. Hewitt. 1999. Vectors, shipping and trade. Pages 45-60 in C. L. Hewitt, M. L. Campbell, R. E. Thresher, and R. B. Martin, eds. Marine biological invasions of Port Phillip Bay. CSIRO Cent. Res. Introduced Mar. Pests Tech. Rep. 20. 
Carlton, J. T. 1996a. Biological invasions and cryptogenic species. Ecology 77:16531655 .

- 1996b. Pattern, process, and prediction in marine invasion ecology. Biol. Conserv. 78:97-106.

Carlton, J. T., J. K. Thompson, L. E. Schemel, and F. H. Nichols. 1990. Remarkable invasion of San Francisco Bay (California, USA) by the Asian clam Potamocorbula amurensis 1. Introduction and dispersal. Mar. Ecol. Prog. Ser. 66:81-94.

Case, T. 1991. Invasion resistance, species build-up and community collapse in metapopulation models with interspecies competition. Biol. J. Linn. Soc. 42:239-266.

Chapman, J. W., and J. T. Carlton. 1991. A test of criteria for introduced species: The global invasion by the isopod Synidotea laevidorsalis (Miers, 1881). J. Crustacean Biol. 11:386-400.

1994. Predicted discoveries of the introduced isopod Synidotea laevidorsalis (Miers, 1881). J. Crustacean Biol. 14:700714.

Coles, S. L., R. C. DeFelice, L. G. Eldredge, and J. T. Carlton. 1999a. Historical and recent introductions of non-indigenous marine species into Pearl Harbor, Oahu, Hawaiian Islands. Mar. Biol. (Berl.) 135: 147-158.

Coles, S. L., R. C. DeFelice, and L. G. Eldredge. 1999b. Nonindigenous marine species introductions in the harbors of the south and west shores of Oahu, Hawaii. Bishop Mus. 'Tech. Rep. No. 15.

Crosby, A. W. 1986. Ecological imperialism: The biological expansion of Europe, 9001900. Cambridge University Press, Cambridge.

Drake, J. A. 1990. The mechanics of community assembly and succession. J. Theor. Biol. 147:213-233.

Elton, C. 1958. The ecology of biological invasions by plants and animals. Methuen and Co., London.

Hatcher, B. G., R. E. Johannes, and A. I. Robertson. 1989. Review of research relevant to the conservation of shallow tropical marine ecosystems. Oceanogr. Mar. Biol. Annu. Rev. 27:337-414.
Hewitt, C. L., and R. B. Martin. 1996. Port surveys for introduced marine speciesbackground considerations and sampling protocols. CSIRO Cent. Res. Introduced Mar. Pests Tech. Rep. 4:1-40.

. 2001. Revised protocols for baseline port surveys for introduced marine species-design considerations, sampling protocols and taxonomic sufficiency. CSIRO Cent. Res. Introduced Mar. Pests Tech. Rep. 22.

Hewitt, C. L., M. L. Campbell, R. E. Thresher, and R. B. Martin, eds. 1999. Marine biological invasions of Port Phillip Bay. CSIRO Cent. Res. Introduced Mar. Pests Tech. Rep. 20.

Lubchenco, J., A. M. Olson, L. B. Brubaker, S. R. Carpenter, M. M. Holland, S. P. Hubbell, S. A. Levin, J. A. MacMahon, P. A. Matson, J. M. Melillo, H. A. Mooney, C. H. Peterson, H. R. Pulliam, L. A. Real, P. J. Regal, and P. G. Risser. 1991. The sustainable biosphere initiative: An ecological research agenda. Ecology 72:371412 .

Norse, E. A., ed. 1993. Global marine biological diversity: A strategy for building conservation into decision making. Island Press, Washington, D.C.

Paulay, G., L. Kirkendale, G. Lambert, and C. Meyer. In press. Anthropogenic biotic interchange in a coral reef ecosystem: A case study from Guam. Pac. Sci.

Pollard, D. A., and P. A. Hutchings. 1990a. A review of exotic marine organisms introduced to the Australian Region. 1. Fishes. Asian Fish. Sci. 3:205-221.

1990b. A review of exotic marine organisms introduced to the Australian Region. 2. Invertebrates and algae. Asian Fish. Sci. 3:223-250.

Robinson, G. R., J. F. Quinn, and M. L. Stanton. 1995. Invasability of experimental habitat islands in a California winter annual grassland. Ecology 76:786-794.

Ruiz, G. M., J. T. Carlton, E. D. Grosholz, and A. H. Hines. 1997. Global invasions of marine and estuarine habitats by nonindigenous species: Mechanisms, extent, and consequences. Am. Zool. 37:621632. 
Ruiz, G. M., W. Fofonoff, J. T. Carlton, M. J. Wonham, and A. H. Hines. 2000. Invasion of coastal marine communities in North America: Apparent patterns, processes, and biases. Annu. Rev. Ecol. Syst. 31:481531.

Southward, A. J., R. S. Burton, S. L. Coles, P. R. Dando, R. DeFelice, J. Hoover, P. E. Parnell, T. Yamaguchi, and W. A. Newman. 1998. Invasion of Hawaiian shores by an Atlantic barnacle. Mar. Ecol. Prog. Ser. 165:119-126.

Stachowicz, J. J., R. B. Whitlatch, and R. W. Osman. 1999. Species diversity and invasion resistance in a marine ecosystem. Science (Washington, D.C.) 286:1577-1579.

Suchanek, T. H. 1994. Temperate coastal marine communities: Biodiversity and threats. Am. Zool. 34:100-114.

Talman, S., J. S. Bité, S. J. Campbell, M. Holloway, M. McArthur, D. J. Ross, and
M. Storey. 1999. Impacts of some introduced marine species found in Port Phillip Bay. Pages 261-274 in C. L. Hewitt, M. L. Campbell, R. E. Thresher, and R. B. Martin, eds. Marine biological invasions of Port Phillip Bay. CSIRO Cent. Res. Introduced Mar. Pests Tech. Rep. 20.

Vinogradov, M. Y. E., E. A. Shushkina, E. I. Musayeva, and P. Y. U. Sorokin. 1989. A newly acclimated species in the Black Sea: The ctenophore Mnemiopsis leidyi (Ctenophora: Lobata). Oceanology 29:220-224.

Willan, R. C., B. C. Russell, N. B. Murfet, K. L. Moore, F. R. McEnnulty, S. K. Horner, C. L. Hewitt, G. M. Dally, M. L. Campbell, and S. T. Bourke. 2000. Outbreak of Mytilopsis sallei (Recluz, 1849) (Bivalvia: Dreissenidae) in Australia. Molluscan Res. 20:25-30.

Williamson, M. 1996. Biological invasions. Chapman and Hall, London. 